\title{
Panorama do Sistema Lagunar de Maricá - RJ: Indicadores de Saneamento vs. Qualidade de Água
}

\author{
Luane Marques Toledo'; Fernanda Carvalho Moreno Wall; Marcelo Obraczkal; André Luís de Sá \\ Salomãol \\ \luanemrqs@gmail.com
}

1. Universidade do Estado do Rio de Janeiro (UERJ), - Rio de Janeiro - Brasil.

\author{
Histórico do Artigo: \\ Recebido em: 15 de junho de $2020 \quad$ Aceito em: 18 de agosto de $2020 \quad$ Publicado em: 30 de abril de 2021
}

Resumo: Um saneamento básico deficiente pode gerar inúmeras consequências prejudiciais a sociedade e ao meio ambiente. Dentre elas destacam-se a poluição dos corpos hídricos e os riscos à saúde pública. Medidas de mitigação desses problemas são necessárias, preferencialmente com base em ações de planejamento e gestão, exigindo maior conhecimento do problema e análise criteriosa das propostas de soluções. Este trabalho tem como objetivo apresentar um panorama ambiental do Sistema Lagunar de Maricá (SLM) baseado nos índices de qualidade de água (IQA) e indicadores de saneamento disponíveis nos bancos de dados do Instituto Estadual do Ambiente (INEA) e do Sistema Nacional de Informações sobre o Saneamento (SNIS), respectivamente. Para uma percepção mais abrangente as lagoas de Maricá e Saquarema foram comparadas considerando os índices e indicadores levantados. Seis pontos de monitoramento realizados pelo INEA foram estudados em corpos d'água afluentes ao SLM e cinco no Sistema Lagunar de Saquarema. Com os resultados verificou-se uma relação entre a qualidade precária das águas do SLM e a falta de saneamento básico adequado nas áreas urbanas de sua bacia hidrográfica, sendo o Canal do Aeroporto de Maricá o que apresentou os piores IQA. Nesse sentido, para possibilitar a melhoria necessária da qualidade da água no SLM em curto prazo, alternativas de engenharia sanitária de emergência podem ser utilizadas, dentre as quais a adoção de um sistema de captação de esgoto em tempo seco, nos moldes do que já vem sendo utilizado com êxito nos complexos lagunares vizinhos Saquarema e Araruama.

Palavras-chave: Sistema Lagunar de Maricá, Indicadores de saneamento, Índice de Qualidade de Água, Captação de tempo seco.

\section{Assessment of the Lagoon System of Marica - RJ: Sanitation Indicators vs. Water Quality}

\begin{abstract}
A poor sanitation system can generate numerous harmful consequences for society and environment These include pollution of water bodies and risks to public health. Mitigation measures for these problems are necessary, preferably based on planning and management actions, requiring greater knowledge of the problem and careful analysis of proposed solutions. This work aims to present an environmental overview of Maricá Lagoon System (MLS) based on water quality indexes (WQI) and sanitation indicators available in the databases of State Environment Institute (INEA) and National Information System on Sanitation (SNIS), respectively. For a more comprehensive perception, the lagoons of Maricá and Saquarema were compared considering the indexes and indicators raised. Six monitoring points performed by INEA were studied in affluent of MLS and five in Saquarema Lagoon System. There was a relationship between the poor quality of the MLS waters and the lack of adequate basic sanitation in the urban areas of its hydrographic basin, with the Maricá Airport channel with the worst WQI. Therefore, one of the main conditions for the environmental revitalization of these lagoons that are vital for Maricá is to obtain a greater range and quality of basic sanitation services provided to the population. To allow the necessary improvement, in the short term, of water quality in MLS, emergency sanitary engineering alternatives can be used, among which the adoption of sewage collection system in dry weather, along the lines of what has already been used with success in the neighboring lagoon complexes such as Saquarema and Araruama.
\end{abstract}

Keywords: Maricá Lagoon System, Sanitation indicators, Water Quality Indexes, Dry Weather System. 

Água

\section{Panorama del Sistema de Lagunas de Maricá - RJ: Indicadores de Saneamiento vs. Calidad del Agua}

Resumen: Un sistema de saneamiento deficiente puede generar numerosas consecuencias perjudiciales para la sociedad y el medio ambiente. Estos incluyen la contaminación de cuerpos de agua y riesgos para la salud pública. Las medidas de mitigación para estos problemas son necesarias, preferiblemente basadas en acciones de planificación y gestión, que requieren un mayor conocimiento del problema y un análisis cuidadoso de las soluciones propuestas. Este trabajo tiene como objetivo presentar una descripción ambiental del Sistema de lagunas de Maricá (SLM) basada en índices de calidad del agua (ICA) e indicadores de saneamiento disponibles en las bases de datos del Instituto Estatal del Medio Ambiente (INEA) y el Sistema Nacional de Información sobre Saneamiento (SNIS), respectivamente. Para una percepción más integral, se compararon las lagunas de Maricá y Saquarema considerando los índices e indicadores propuestos Seis puntos de monitoreo realizados por INEA fueron estudiados en afluentes de MLS y cinco en el Sistema de lagunas de Saquarema. Hubo una relación entre la mala calidad de las aguas de la SLM y la falta de saneamiento básico adecuado en las áreas urbanas de su cuenca hidrográfica, con el canal del aeropuerto de Maricá con el peor ICA. Por lo tanto, una de las principales condiciones para la revitalización ambiental de estas lagunas que son vitales para Maricá es obtener una mayor variedad y calidad de los servicios básicos de saneamiento prestados a la población. Para permitir la mejora necesaria, a corto plazo, de la calidad del agua en SLM, se pueden utilizar alternativas de ingeniería sanitaria de emergencia, entre las cuales se encuentra la adopción del sistema de recolección de aguas residuales en clima seco, en línea con lo que ya se ha utilizado con éxito en complejos de lagunas vecinas Saquarema y Araruama.

Palabras clave: Sistema de lagunas de Maricá, Panorama Ambiental, Indicadores de saneamiento, Índices de Calidad del Agua, Captura de clima seco.

\section{INTRODUÇÃo}

Bacias hidrográficas localizadas em áreas urbanas são geralmente impactadas por uma ocupação crescente e desordenada, sem planejamento prévio e infraestrutura adequada de saneamento básico (ANA, 2019; ROSSO, 2008). Uma das consequências do crescimento acelerado e sem planejamento das populações mundiais é o aumento no consumo de água e consequentemente da geração de esgotos (efluentes domésticos, municipais e industriais). Já a falta de um planejamento prévio tem como consequência a poluição e degradação ambiental (GIORDAN0 et al., 2019), acarretando também o comprometimento da saúde pública com a propagação de doenças de veiculação hídrica (VON SPERLING, 2005).

Essa grande precariedade nos serviços de saneamento básico pode ser constatada no município de Maricá, pertencente a Região Metropolitana do Rio de Janeiro, que nos últimos anos também apresentou a maior taxa de crescimento populacional dentre todos os municípios brasileiros (ANA, 2017). Com uma taxa anual de 5,2\% de crescimento populacional entre os anos de 2000 e 2010, Maricá superou em muito a média Nacional de 1,2\% para o mesmo período (ATLAS BRASIL, 2013). Em grande parte, tal crescimento pode ser relacionado à sua proximidade com a capital do estado e com um importante polo comercial e industrial do estado (Macaé e o 
Complexo Petroquímico do Rio de Janeiro - COMPERJ), possibilitando inúmeras oportunidades de negócios e investimentos. No entanto, caso não sejam tomadas medidas e ações de preservação, tais investimentos podem resultar numa degradação ambiental da região (INEA, 2018).

0 Sistema Lagunar de Maricá (SLM) está localizado na região costeira do município e se constituiu em um atrativo fundamental para o seu desenvolvimento, principalmente em função da pesca (FRANC0 et al., 2019), principal pilar econômico do município até o início dos anos 50 (LOUREIR0 et al., 2010). Por outro lado, o entorno das lagoas vêm sendo foco de uma intensa urbanização e ocupação por condomínios, sendo que somente uma pequena parte das edificações possui tratamento primário de seus efluentes (WALL; TOLEDO; OBRACZKA, 2019).

Os resultados dessas ações antrópicas no município podem ser quantificados com base no Ranking ABES referente à universalização do saneamento em municípios com mais de 100 mil habitantes, que utiliza cinco indicadores de saneamento do SNIS. Com base em dados de 2015, em uma pontuação que varia de 0 a 500 pontos, Maricá pontuou 275,82, ficando somente em $199^{\circ}$ lugar dentre os 231 municípios contemplados pelo ranking (ABES, 2017).

Segundo Alegre et al. (2016), indicador de desempenho é um meio de se medir a eficiência e/ou eficácia de uma entidade de modo quantitativo, geralmente são calculados pela razão entre duas variáveis adimensionais ou não (STAHRE; ADAMSSON, 2004). Seu emprego é crescente no Brasil e no mundo, tornando-se um instrumento cada vez mais presente nos sistemas de planejamento e gestão de saneamento (VON SPERLING; VON SPERLING, 2013).

Os indicadores de saneamento utilizados pelo SNIS e no Plano Nacional de Saneamento Básico (PLANSAB) são: a) Abastecimento de água: Índice de atendimento da população com rede de abastecimento de água em relação a população total; b) Coleta de esgoto: Índice de atendimento da população por rede coletora de esgotos em relação a população total; c) Tratamento de esgoto: Índice de esgoto total tratado em relação ao total de água consumida, com o coeficiente transformação agua/esgoto de 0,80 (ABES, 2015).

0 Índice de Qualidade de Água (IQA) é um outro indicador muito utilizado para avaliar a qualidade dos ambientes aquáticos, sendo uma ferramenta bastante aplicada no 
Panorama do Sistema Lagunar de Maricá - RJ: Indicadores de Saneamento vs. Qualidade de Água

monitoramento ambiental. A partir da integração dos parâmetros físicos, químicos e microbiológicos (geralmente indicadores de contaminação por lançamento de esgoto) em um único número, é possível estimar um cenário abrangente e mais realista do nível de qualidade de água de um corpo hídrico (TIAN et al. 2019). Diferentes métodos de avaliação foram propostos nos últimos anos, a nível nacional e internacional, numa tentativa de converter os dados de qualidade da água em informações compreensíveis à população em geral e agentes públicos com a complexidade e simplicidade necessárias (ABBASNIA et al.2019; MUKATE et al. 2019).

Este trabalho tem como objetivo avaliar a relação entre as condições sanitárias do município de Maricá e a degradação das águas da bacia hidrográfica do SLM, utilizando dados como indicadores de saneamento e os índices de qualidade de água (IQA).

\section{MATERIAL E MÉTODOS}

\section{Local de estudo}

0 Sistema Lagunar de Maricá (SLM) está localizado no município de Maricá, a cerca de $60 \mathrm{~km}$ da capital do Estado do Rio de Janeiro (ERJ). 0 complexo lagunar situa-se na Região Hidrográfica V - Baía de Guanabara, mais especificamente na Bacia do SLM, constituindo um dos atributos mais importantes da região e um dos maiores sistemas lagunares do estado. Este sistema é composto pelas lagoas de Araçatiba, Jacaroá, Guarapina, Jaconé, da Barra e do Padre, compreendendo uma área de aproximadamente $330 \mathrm{~km}^{2}$, sendo que toda sua bacia contribuinte está contida nos limites do município de Maricá (Figura 1). Entre os principais corpos hídricos que deságuam nas lagoas deste sistema destacam-se os Rios Caranguejo, Ludígero e Mombuca (INEA, s.d.). 


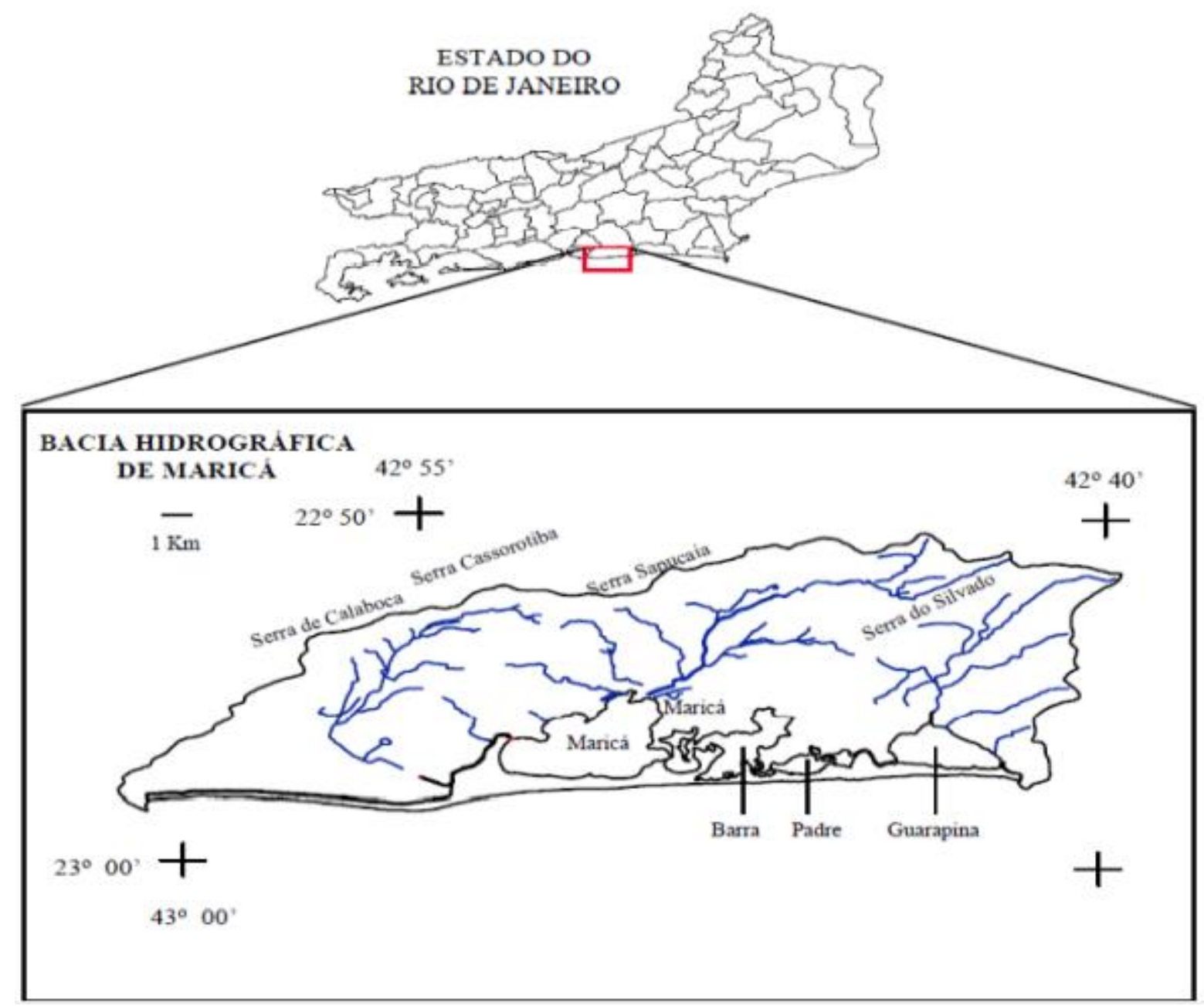

Figura 1 - Localização da Lagoa e do município de Maricá no estado do Rio de Janeiro. Fonte: Cidade Brasil, s.d.; Ambiental, 2014.

Segundo Amador (2007), as lagunas costeiras que compõem o SLM são produzidas pela barragem de estuários, enseadas, baías e braços de mar por cordões de restinga. Assim sendo, essas lagoas apresentam sinais dos antigos canais de comunicação com o mar, estando eles abertos permanentemente ou de forma sazonal.

Notadamente nas últimas décadas, o SLM vem sofrendo diversos impactos relacionados às atividades humanas como a ocupação indevida das margens, causando assoreamentos, redução de espelho d'água e mata ciliar (WALL; TOLEDO; OBRACZKA, 2019). Segundo esses mesmos autores, efeitos como a redução da balneabilidade e da biodiversidade local já podem ser sentidos em função do aumento da poluição em suas águas causada pelo lançamento indevido de esgoto e disposição de resíduos sólidos, provocando eutrofização das águas e mortandade de peixes (Figura 2). 

Água
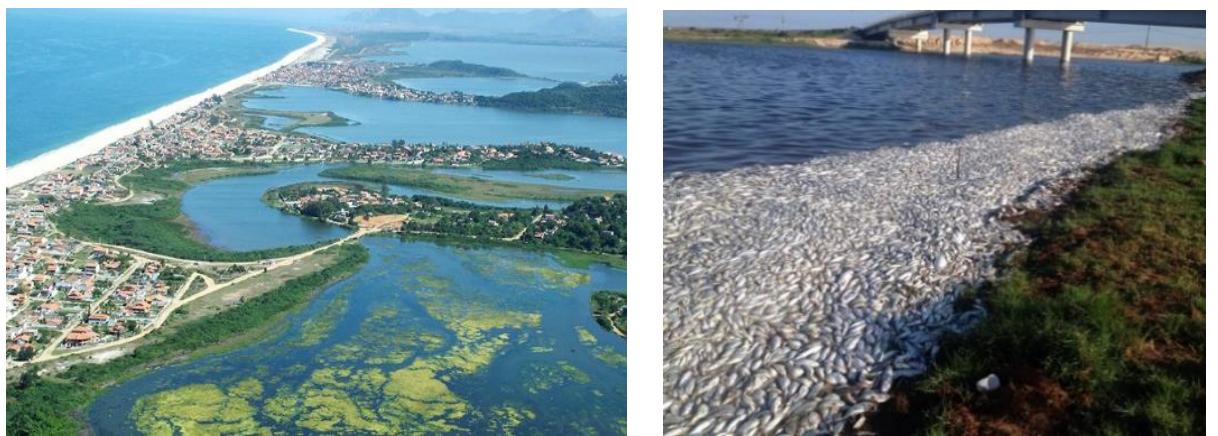

Figura 2 - Eutrofização e mortandade de peixes verificadas no Sistema Lagunar de Maricá. Fonte: Prefeitura de Maricá

A extração de areia, exploração de argila e a pecuária de bovinos e equinos também são atividades bastante desenvolvidas na região (CRUZ, 2010), e acabam por influenciar direta e negativamente nas características físicas, biológicas e químicas das lagoas. De acordo com Cruz (2010), a criação de bovinos e equinos proporciona um aumento considerável das concentrações de nutrientes e sólidos em suspensão nas águas, resultando em um processo inevitável de eutrofização e assoreamento de todo o sistema. Com isso, as atividades turísticas e de pesca artesanal são as principais prejudicadas.

A extração de areia, exploração de argila e a pecuária de bovinos e equinos também são atividades bastante desenvolvidas na região (CRUZ, 2010), e acabam por influenciar direta e negativamente nas características físicas, biológicas e químicas das lagoas. De acordo com Cruz (2010), a criação de bovinos e equinos proporciona um aumento considerável das concentrações de nutrientes e sólidos em suspensão nas águas, resultando em um processo inevitável de eutrofização e assoreamento de todo o sistema. Com isso, as atividades turísticas e de pesca artesanal são as principais prejudicadas.

\section{Método de avaliação das condições de saneamento básico}

A metodologia adotada baseou-se em uma etapa inicial de levantamento de referências bibliográficas, dados de saneamento e legislações pertinentes ao tema. A partir deste levantamento foi construída uma base de dados possibilitando um melhor conhecimento da situação atual bem como o desenvolvimento do estudo e da avaliação pretendida.

Numa segunda etapa, a partir da disponibilidade das informações em bancos de dados e sistemas de informação de referência como o SNIS e INEA, foram definidos os índices e indicadores a serem empregados no estudo. Estes foram selecionados baseados nos critérios de relevância e aderência aos objetivos propostos, assim como nos impactos negativos causados pela ausência destes serviços básicos de saneamento, tanto para a saúde da população, como 
na degradação dos corpos hídricos. Sendo assim, os indicadores de saneamento adotados foram: índice de coleta e tratamento de esgoto; índice de atendimento urbano de água; e índice de consumo médio per capita de água. Estes são disponibilizados pela concessionária local (CEDAE) através do SNIS, tendo sido utilizado os dados do período de 2010 a 2016.

Com base nos índices e indicadores adotados, e de forma a proporcionar um maior embasamento a pesquisa, foi também selecionado um sistema de lagoas com características similares as de Maricá para possibilitar uma comparação. Após uma avaliação prévia dos complexos lagunares no ERJ, o Sistema Lagunar de Saquarema foi selecionado. Entre os aspectos de similaridade que podem ser elencados, destacam-se: proximidade, importância das lagoas nos contextos locais, características geográficas, geomorfológicas, climáticas/ pluviométricas, além das antrópicas como de uso e ocupação do solo e sazonalidade da população local (BIDEGAIN; PEREIRA, 2005).

\section{Método de avaliação das condições ambientais dos corpos hídricos}

A metodologia adotada se baseou no Índice de Qualidade de Água (IQA), utilizando-se o cálculo em conformidade com a Agência Nacional de Águas (ANA, 2005). 0 IQA é o principal instrumento utilizado pelo INEA para avaliação da qualidade das águas (INEA, s/d) no ERJ. No cálculo do IQA foram utilizados os parâmetros físico-químicos e biológicos relacionados aos principais corpos hídricos que deságuam no sistema lagunar e que são monitorados pelo INEA, sendo eles: oxigênio dissolvido (0D), coliformes fecais, potencial hidrogeniônico (pH), demanda bioquímica de oxigênio (DB05), temperatura, nitrogênio total ou nitrato, fósforo total ou fosfato, turbidez e resíduo total. 0 cálculo para obtenção dos índices é realizado a partir de uma média ponderada, seguindo o critério de pesos diferenciados aos parâmetros avaliados de acordo com ANA (2005). 0 valor final da pontuação de cada índice varia entre 0 e 100, numa escala crescente de qualidade ambiental, dividida em cinco classes com cores e classificação correspondente (Tabela 1).

Tabela 1 - Índice de qualidade de água (IQA): Classificação numérica (0 - 100) e qualitativa com escala de cores correspondentes.

Fonte: ANA, 2005.

\begin{tabular}{|l|l|}
\hline Faixa de IQA & Avaliação da qualidade da água \\
\hline $91-100$ & Ótima \\
\hline $71-90$ & Boa \\
\hline $51-70$ & Razoável \\
\hline $26-50$ & Ruim \\
\hline $0-25$ & Péssima \\
\hline
\end{tabular}


Panorama do Sistema Lagunar de Maricá - RJ: Indicadores de Saneamento vs. Qualidade de Água

Esses parâmetros remetem, em sua maioria, à contaminação promovida pelo lançamento de esgotos domésticos e cargas orgânicas industriais nos corpos d'água (CETESB, 2003). Apesar de largamente empregado, o cálculo do IQA apresenta limitações (CETESB, 2003), visto que um número significativo de poluentes não é considerado no seu cálculo, entre eles os provenientes de atividades agrícolas e industriais, como metais pesados, pesticidas e compostos orgânicos (ANA, 2005).

\section{Pontos amostrais de coleta de dados}

0 acompanhamento da qualidade das águas interiores no ERJ é realizado pelo INEA em pontos/estações de monitoramento distribuídos pelas nove bacias hidrográficas fluminenses e por seus respectivos corpos hídricos (INEA, s/d).

Os pontos de monitoramento adotados para os sistemas lagunares de Maricá e Saquarema situam-se em canais, rios e seus tributários (Figuras 3 e 4). 0s índices e indicadores de saneamento referentes a estes pontos foram levantados nas bases de dados do SNIS (2010 a 2016) e INEA (2014 a 2017).

No SLM, os dados para o cálculo do IQßA são provenientes do monitoramento de três canais Aeroporto (AM000), Itaipuaçu (CI005) e Buriche (BU010) e três rios - Ludigero (LU010), Mombuca (Mn010) e Caranguejo (CR040) (Figura 3). Em Saquarema, os cinco corpos hídricos monitorados são os rios Jundiá (JN500), Seco (SE0200), do Padre (PD230), Tinguí (TN020) e Roncador (RD015) (Figura 4).

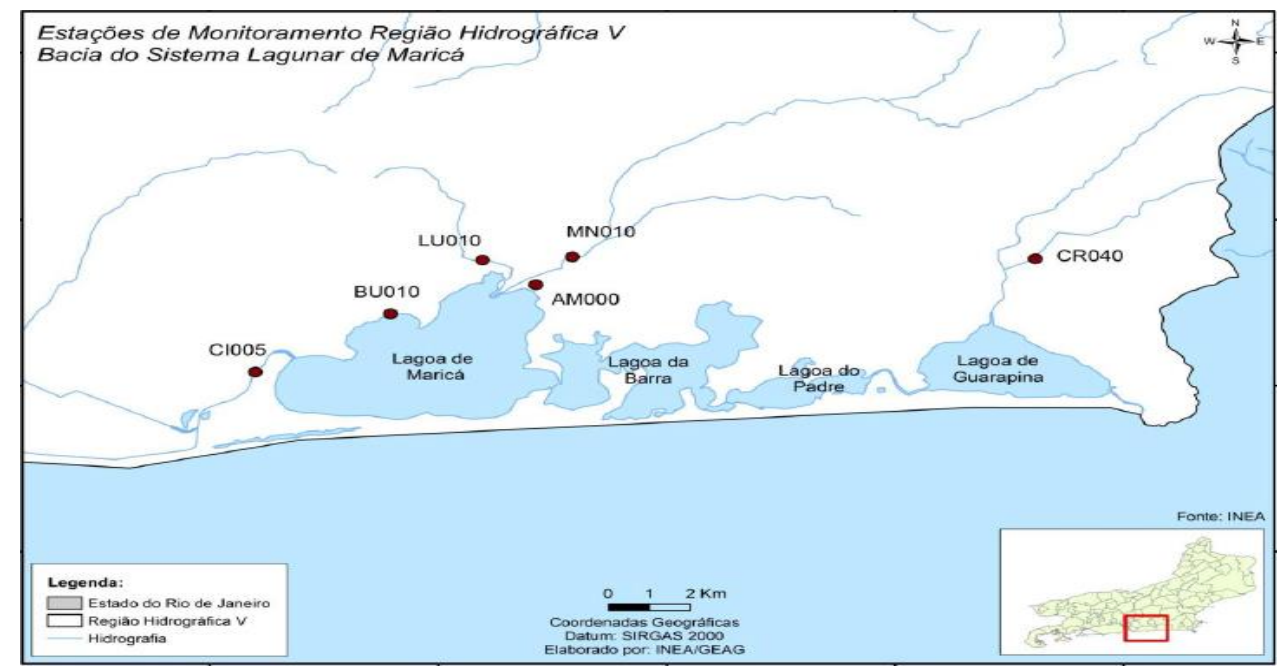

Figura 3 - Estações de Monitoramento em afluentes ao Sistema Lagunar de Maricá: CI005 Itaipuaçu; BU010 - Buriche; LU010 - Ludigero; MN010- Mombuca; AM000- Aeroporto e CR040Caranguejo.Fonte: INEA, 2017. 


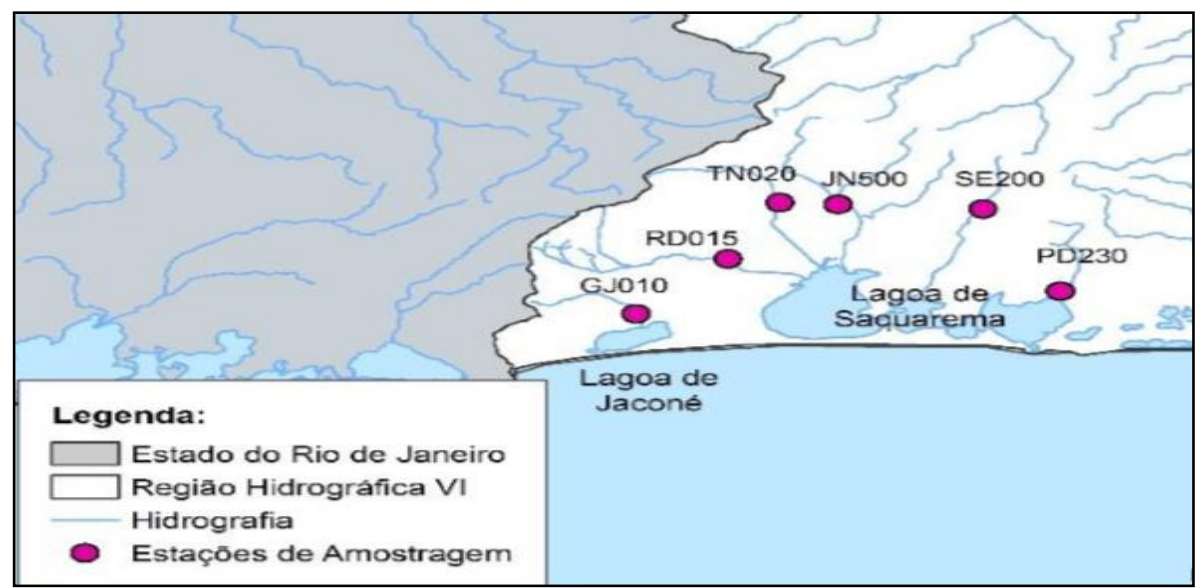

Figura 4 - Estações de Monitoramento em afluentes ao Sistema Lagunar de Saquarema: RD015 - Roncador; TN020 - Tinguí; JN500 - Jundiaí; SE200 - Seco e PD230 - Padre.

Fonte: INEA, 2017.

\section{RESULTADOS E DISCUSSÃ0}

\section{Indicadores de saneamento}

Segundo dados da ANA (2017), o município de Maricá apresentou valores ínfimos para os índices de saneamento básico: apenas 2\% tiveram seu esgoto coletado e tratado,15\% das residências tiveram seu esgoto coletado, porém sem tratamento, e cerca de 52\% fizeram uso de fossa séptica (IBGE, 2010). Na inexistência de rede coletora, o emprego de fossa séptica pressupõe que o seu efluente foi: a) encaminhado à rede de drenagem (quando disponível); b) retirado por caminhão limpa-fossa, ou c) preferencialmente, por questões de menor custo, infiltrado no solo através de sumidouros.

Observando o censo realizado pelo IBGE em 2010 (Figura 5), foi possível aferir que além de fossas sépticas, 28\% dos domicílios de Maricá fizeram uso das fossas rudimentares como forma de destinação final do esgoto doméstico. A rede geral foi o destino do esgoto adotado por apenas $12 \%$ dos domicílios.
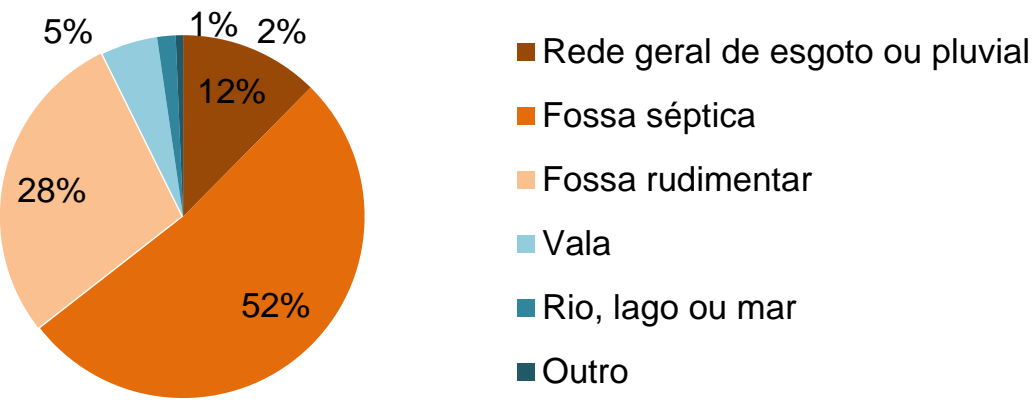

Figura 5 - Destinação final ou formas de tratamento de esgoto doméstico adotados nas residências de Maricá.

Fonte: IBGE, 2010. 
Panorama do Sistema Lagunar de Maricá - RJ: Indicadores de Saneamento vs. Qualidade de Água

No período estudado, cerca de $80 \%$ da população das áreas mais adensadas de Maricá e que se localizavam próximas ao Centro do município faziam uso de fossas sépticas ou rudimentares, sem a devida operação/manutenção (em função dos custos), ou ainda, utilizavam sumidouros, infiltrando o efluente gerado no solo. Assim, grande parte desses efluentes não atingia o grau de tratamento e os limites específicos de lançamento de acordo com a legislação pertinente (BRASIL, 2011), sendo encaminhados inadequadamente para os corpos hídricos locais.

Outro ponto que deve ser destacado é que, em função das carências do sistema de abastecimento público de água local, grande parte da população fazia uso de alternativas de abastecimento de água como captação de água de chuva, caminhões pipa ou poços freáticos como forma principal de abastecimento de suas residências (OHNUMA et al., 2019). No entanto, tendo em vista uso maciço de sumidouros e fossas rudimentares como destinação dos esgotos através de infiltração no solo, o emprego de poços freáticos para suprir as demandas de água era altamente contraindicado e mesmo alarmante do ponto de vista sanitário e de saúde pública (CONEM, 2015; AMBIENTAL, 2014). A Tabela 2 reúne alguns dados/índices referentes ao saneamento básico (abastecimento de água e esgotamento sanitário) no município de Maricá.

Tabela 2 - Comparação dos dados de cobertura dos serviços de saneamento básico no município de Maricá.

\begin{tabular}{lllll}
\hline $\begin{array}{l}\text { Banco } \\
\text { Dados }\end{array}$ & $\begin{array}{l}\text { de } \\
\text { abastecimento de }\end{array}$ & $\begin{array}{l}\text { Coleta } \\
\text { esgoto }\end{array}$ & $\begin{array}{l}\text { de } \\
\text { esgoto }\end{array}$ & $\begin{array}{l}\text { Tratamento } \\
\text { esgoto }\end{array}$ \\
\hline IBGE & $18,95 \%$ & $12,38 \%$ & $64,40 \%$ & \\
ANA & - & $17,00 \%$ & $54,00 \%$ & \\
SNIS & $57,98 \%$ & $16,86 \%$ & $34,65 \%$ & \\
ABES & $55,94 \%$ & $11,02 \%$ & $6,06 \%$ & \\
\hline
\end{tabular}

Fonte: IBGE, 2010; ANA (2013); SNIS (2013, 2016); ABES (2019).

Nota-se que os dados obtidos apresentam resultados discrepantes, fato que pode ser justificado não somente pelas distintas fontes e datas de publicação dos dados. Além disso, o SNIS e a ABES obtêm seus dados a partir das concessionárias prestadoras de serviço enquanto o IBGE realiza consultas à população; já a ANA realiza levantamentos de campo. Não obstante, ainda que os valores obtidos sejam distintos, todos corroboram para uma avaliação da condição do saneamento básico local como muito precária. Nesse sentido, cabe ressaltar que o uso de fossas sépticas representava a maior parte da destinação final dos esgotos domésticos em Maricá, englobando 51,9\% dos 64,4\% indicados pelo IBGE (2010) e 52\% dos 54\% indicados pela ANA (2013). 
Mesmo com o crescimento da população (17,6\%) tendo sido acompanhado por um relativo avanço da infraestrutura de saneamento básico, tanto no que se refere ao abastecimento de água $(16,4 \%)$ como ao esgotamento sanitário (16,3\%) (Figura 6), observada se que a grande carência de infraestrutura de saneamento básico no município permanece, reforçando os dados apresentados pelas diferentes bases de dados consultadas.

Foi possível realizar uma análise comparativa entre a evolução dos índices de saneamento adotados para os municípios de Maricá e Saquarema. No tocante aos dados de indicadores de saneamento de Maricá, estes se apresentaram em patamares muito inferiores quando comparados com os do município de Saquarema. Alguns indicadores apresentaram inclusive uma redução nas taxas de atendimento ao longo dos últimos anos (Tabela 3).

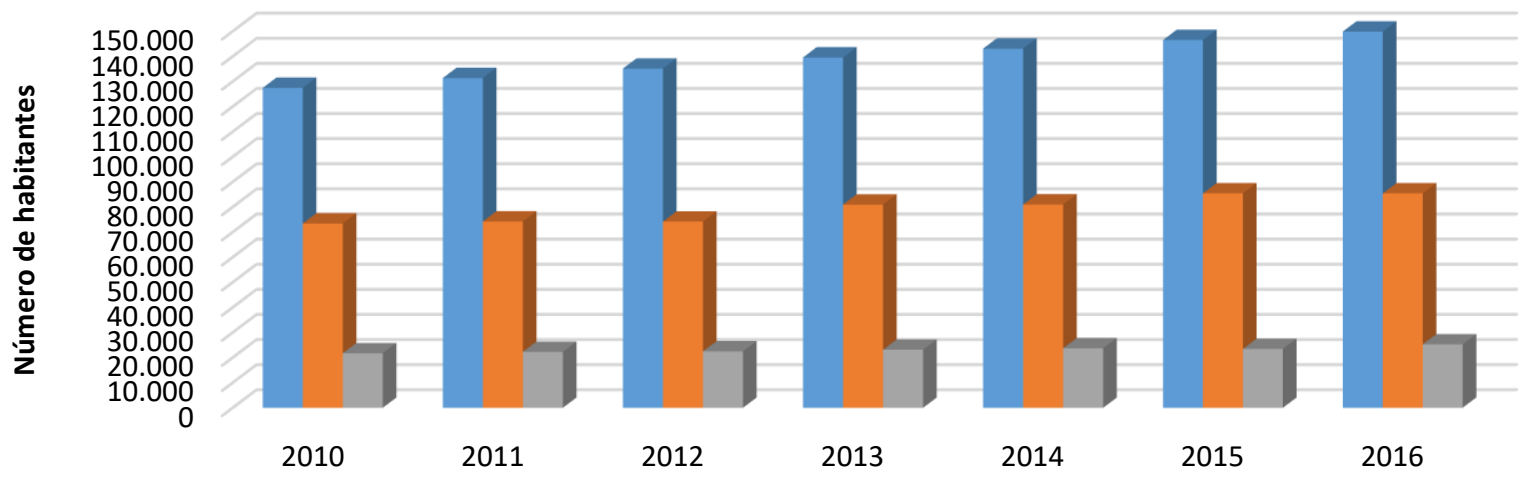

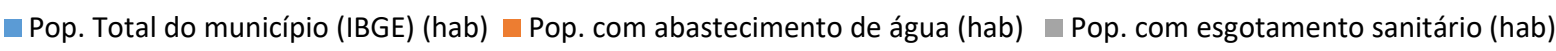

Figura 6 - População total e população atendida por redes gerais de abastecimento e esgotamento para o município de Maricá no ERJ.

Fonte: Adaptação do SNIS, 2016.

Tabela 3 - Comparativo dos Indicadores de Saneamento para os municípios de Maricá e Saquarema.

\begin{tabular}{|c|c|c|c|c|c|c|}
\hline 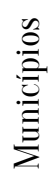 & $\begin{array}{l}\text { Período de } \\
\text { avaliação }\end{array}$ & $\begin{array}{l}\text { População } \\
\text { (mil hab.) }\end{array}$ & $\begin{array}{l}\text { Coleta de } \\
\text { esgoto (\%) }\end{array}$ & $\begin{array}{l}\text { Tratamento } \\
\text { de esgoto } \\
(\%)^{* *}\end{array}$ & $\begin{array}{l}\text { Atendimento } \\
\text { urbano de } \\
\text { água } \\
(\%)\end{array}$ & $\begin{array}{l}\text { Consumo médio } \\
\text { per capita de } \\
\text { água } \\
\text { (l/hab./dia) }\end{array}$ \\
\hline \multirow{7}{*}{ 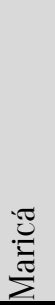 } & 2010 & 127.461 & 17.0 & 66.6 & 57.6 & 214.4 \\
\hline & 2011 & 131.355 & 17.0 & 66.6 & 56.5 & 153.3 \\
\hline & 2012 & 135.121 & 16.6 & 68.3 & 54.9 & 156.0 \\
\hline & 2013 & 139.552 & 16.6 & 68.3 & 58.0 & 150.0 \\
\hline & 2014 & 143.111 & 16.6 & 34.5 & 56.6 & 143.9 \\
\hline & 2015 & 146.549 & 16.0 & 34.1 & 58.3 & 140.0 \\
\hline & 2016 & 149.876 & 16.9 & 34.7 & 57.0 & 129.5 \\
\hline \multirow{4}{*}{ 节 } & 2010 & 74.234 & 69.3 & - & 94.0 & 52.2 \\
\hline & 2011 & 75.906 & 82.8 & 100.0 & 100.0 & 49.5 \\
\hline & 2012 & 77.522 & 90.0 & 100.0 & 93.9 & 51.9 \\
\hline & 2013 & 79.421 & 59.5 & 100.0 & 94.0 & 57.3 \\
\hline
\end{tabular}


Panorama do Sistema Lagunar de Maricá - RJ: Indicadores de Saneamento vs. Qualidade de Água

\begin{tabular}{cccccc}
\hline 2014 & 80.915 & 53.3 & 100.0 & 94.4 & 71.8 \\
2015 & 82.359 & 56.6 & 100.0 & 95.6 & 107.5 \\
2016 & 83.750 & 55.9 & 100.0 & 97.3 & 110.3 \\
\hline
\end{tabular}

Ao analisar os dados, observou-se que o índice de abastecimento de água em Maricá apresentou alterações ínfimas no período estudado, com apenas cerca de 60\% da população tendo acesso a esse serviço. Por outro lado, mesmo apresentando uma pequena variação positiva na época estudada, Saquarema aumentou a abrangência de 94\% em 2010 para 97\% em 2016 (SNIS, 2016). Nesse mesmo período analisado, a coleta de esgoto em Maricá se manteve estável e em torno de 17\%. Saquarema, no entanto, aumentou seu serviço de coleta de efluentes de $70 \%$ para $90 \%$ entre 2010 e 2012. Após 2013, porém, sua abrangência caiu bastante, alcançando 56\% de cobertura em 2016. Pelo grau anormal de redução, acredita-se que essa queda possa estar também associada a uma mudança na metodologia de cálculo do indicador.

Também baseado na média brasileira - de $61 \%$ de esgoto coletado e 43\% de tratamento (ANA, 2017) - pode ser demonstrada a grande deficiência nos serviços de saneamento básico oferecidos no município de Maricá. Tal deficiência ficou ainda mais destacada quando os dados de Maricá são comparados com as metas do Plano Nacional de Saneamento Básico (PLANSAB): para o ano marco de 2018, o Plano previa a coleta de esgoto de 90\% (para domicílios urbanos e rurais) e 94\% (para domicílios urbanos) e ainda 63\% de tratamento do efluente coletado (PLANSAB, 2013).

Embora o município de Saquarema tenha apresentado uma queda significativa quanto à coleta de esgoto em 2013, sua abrangência aumentou entre 2013 e 2016, mantendo-se próximo a $60 \%$, sendo esse um valor mais condizente com a média nacional e bastante superior aos dados de Maricá. Cabe ressaltar que 100\% do esgoto coletado em Saquarema foi tratado, alcançando as metas do Plano Nacional de Saneamento Básico (PLANSAB).

Maricá dispõe de uma rede coletora de esgoto com extensão reduzida, limitada a algumas poucas ruas na região central do município. Segundo o Plano Municipal de Saneamento Básico - PMSB (CONEM, 2015), o município possuía quatro ETEs em operação, sendo duas na região central (ETE Araçatiba e ETE Pedreiras) e duas ETEs de pequeno porte que atendiam exclusivamente a dois condomínios Minha Casa Minha Vida. 0 atendimento com coleta e tratamento de efluentes para o restante dos domicílios do município pode ser considerado como irrisório ou quase inexistente (CONEN, 2015; AMBIENTAL, 2014). Além disso, as ETEs Pedreira e Araçatiba se encontravam inoperantes ou em más condições de funcionamento, operando abaixo de sua capacidade originalmente projetada. Este fato foi também comprovado em estudo 
elaborado pela AMBIENTAL (2014), ao destacar que a ETE de Araçatiba operava de forma inadequada, além de receber somente uma parcela desprezível dos esgotos da área central do município.

Uma alternativa adotada pelo município nos primeiros anos da presente década foi um projeto executado com verba da Petrobrás, que previa a implantação de um emissário submarino para destinação final dos efluentes domésticos, e que incluía a implantação de redes elevatórias de esgoto em boa parte da área urbana. Porém, além do trecho submarino do emissário, apenas um pequeno trecho da rede projetada foi implantado em um bairro da região central do município. Até o ano de 2018, as obras se encontravam paradas e inacabadas (AMBIENTAL, 2014; WALL; TOLEDO; OBRACZKA, 2019). Por outro lado, o município de Saquarema dispõe de três ETEs em funcionamento, sendo duas com tratamento secundário (uma com sistemas de lodos ativados e a outra com uma lagoa aerada, seguida de lagoa de decantação/facultativa/maturação) e uma com tratamento terciário (sistema de reator anaeróbio seguido de filtro aeróbio e decantador) (WALL; TOLED0; OBRACZKA, 2019).

\section{Avaliação das condições de qualidade das águas superficiais}

As Figuras 7 e 8 retratam os valores médios anuais obtidos com o cálculo do IQA para os corpos hídricos monitorados que deságuam nos sistemas lagunares de Maricá e Saquarema, no período de 2014 até 2017.

O IQA calculado para os pontos de monitoramento no SLM apresentou variações de qualidade de "Razoável" a "Péssima" (em pelo menos 4 das 6 estações) durante todo o período de monitoramento. No geral, os valores de IQA para o SLM foram: 34,1\% Razoável; 45,45\% Ruim e 20,45\% Péssimo. Não foi verificado nenhum resultado acima dos 70 pontos ("Boa” a "Ótima”).

0 Canal do Aeroporto de Maricá foi o que apresentou os piores resultados, o que pode ser explicado pelo fato de atravessar a região central e mais urbanizada do município e que não dispõe de sistema de esgotamento sanitário, desaguando em seguida na Lagoa de Maricá. Vale destacar que esse deságue ocorre próximo da ETE de Araçatiba, a maior do município.

Aliados as carências do sistema de coleta/tratamento/destinação final dos esgotos, os inúmeros despejos de esgotos in natura nesse canal, em função da baixa cobertura/atendimento da rede de esgoto, vêm contribuindo para a crescente degradação ambiental do SLM (AMBIENTAL, 2014; CONEM, 2015). 


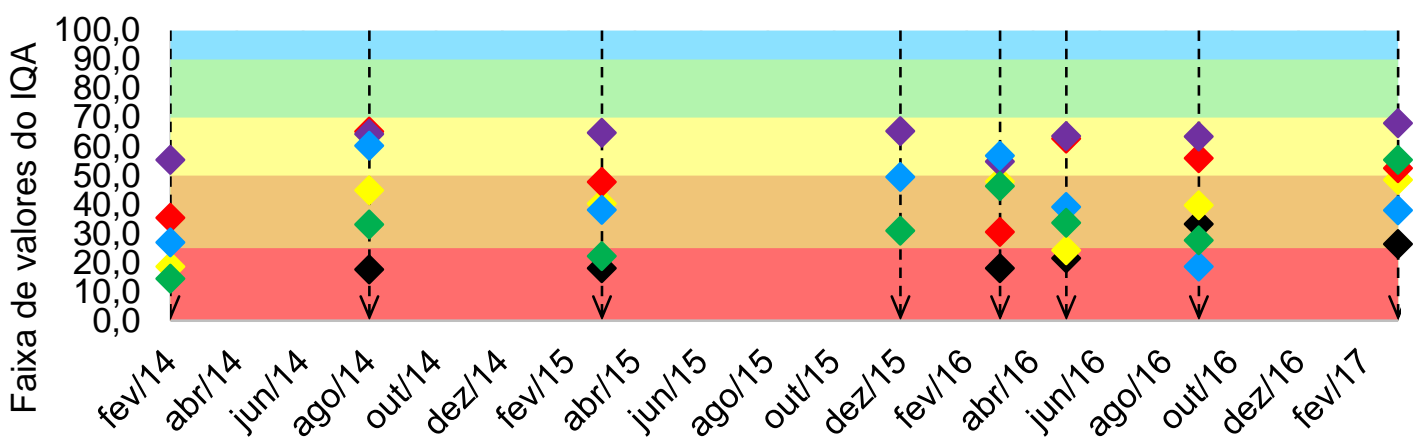

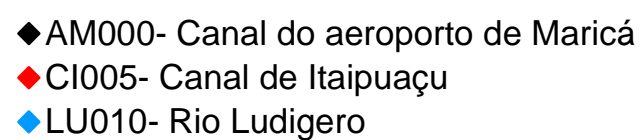

- AM000- Canal do aeroporto de Maricá LU010- Rio Ludigero

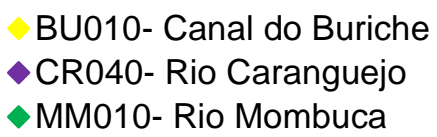

BU010- Canal do Buriche

MM010- Rio Mombuca

Figura 7 - Monitoramento dos dados de IQA de rios e canais afluentes ao Sistema Lagunar de Maricá no período de 2014 a 2017.

Fonte: Adaptação do INEA (2014 a 2017).

Mesmo com todos seus resultados de IQA apenas na faixa de “Razoável”, o Rio Caranguejo foi o que apresentou os melhores resultados entre os pontos de monitoramento. Tal fato pode ser creditado ao fato de a região do seu entorno apresentar uma menor taxa de ocupação tanto de suas margens como de sua área total de drenagem e ainda devido à proximidade ao Canal de Ponta Negra, que favorece a troca de água com o mar.

Já o IQA calculado para os pontos de monitoramento no Sistema Lagunar de Saquarema apresentou variações de qualidade de "Boa" a "Péssima”. (Figura 8). Três rios apresentaram resultados de classificação "Boa" na maioria das análises realizadas, enquanto a classificação de "Péssima" só foi verificada para o Rio do Padre. Em geral, os valores de IQA para o Sistema Lagunar de Saquarema apresentaram as seguintes classificações: 10,25\% “Boa”; 53,85\% "Razoável”; 28,20\% "Ruim” e 7,7\% "Péssima”. 0 Rio do Padre foi o que apresentou os piores resultados enquanto os Rios Tinguí, Roncador e Seco apresentaram os melhores índices.

De uma maneira geral, os valores do IQA dos rios que deságuam no Sistema Lagunar de Saquarema foram superiores aos dos rios e canais que deságuam no SLM, durante todo o período analisado. Cerca de 65\% dos resultados em Saquarema apresentaram classificação entre "Razoável” e "Boa” contra apenas 35\% (e somente "Razoável”) em Maricá. Pode ser também constatado que em ambos os sistemas lagunares, os rios e canais que apresentaram os piores IQA foram justamente aqueles que atravessavam as áreas mais degradadas e urbanizadas de 
suas respectivas bacias, ou seja, mais sujeitos as ações antrópicas como lançamentos de esgotos não tratados.

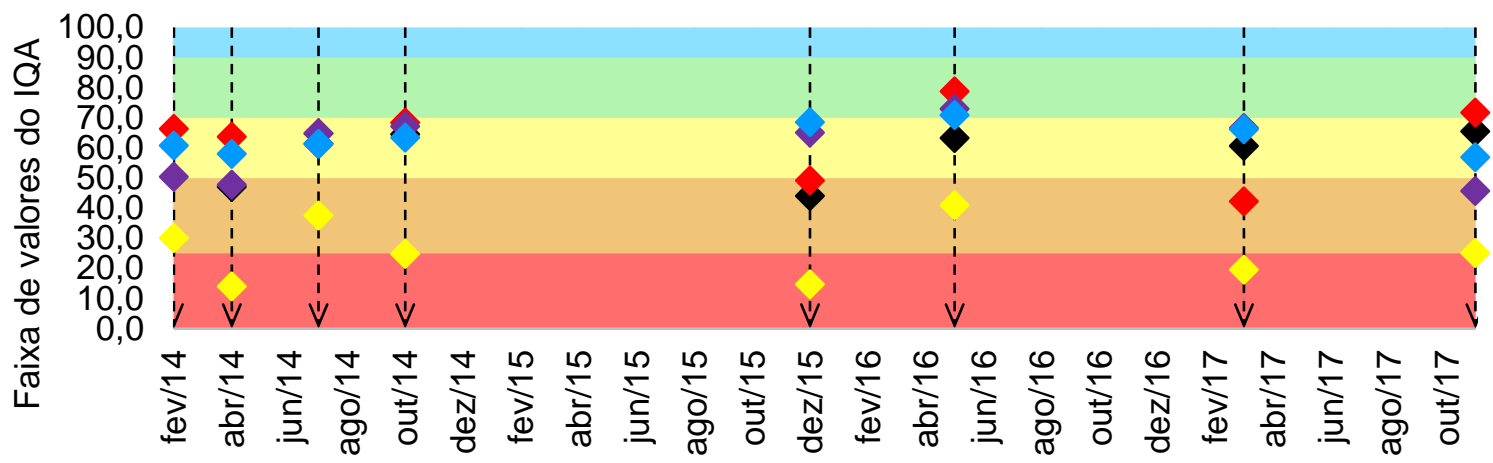

\section{• JN0500- Rio Jundiá}

Figura 8 - Monitoramento dos dados de IQA dos rios afluentes ao Sistema Lagunar de Saquarema no período de 2014 a 2017.

Fonte: Adaptação do INEA (2014 a 2017).

\section{Indicativo de soluções para redução da degradação ambiental do SLM}

A partir dos dados de monitoramento referentes ao período estudado, pode ser constatado que a situação da poluição e da degradação ambiental das águas superficiais do SLM demanda há tempos uma solução emergencial e abrangente de coleta/captação, encaminhamento e disposição final dos esgotos da área urbana do município.

A implantação de um sistema convencional de saneamento, com adoção de um sistema separador absoluto, embora definitiva e mais eficaz, demanda mais tempo e tende a ser muito onerosa, envolvendo a construção de centenas de $\mathrm{km}$ de redes separativas. Assim, há a necessidade de se implantar soluções emergenciais para mitigar a curto prazo os lançamentos de elevadas cargas poluentes nos corpos hídricos do município e seus impactos e efeitos negativos.

Uma alternativa a curto prazo poderia ser a adoção de um sistema de captação de tempo seco. Esta tecnologia intercepta os esgotos in natura irregularmente despejados em galerias de águas pluviais, valões, canais ou mesmo nos próprios rios. Para isso é utilizada uma barragem no leito desses dispositivos de escoamento, a montante da qual é introduzido um sistema de captação dos esgotos (Figura 9). Os esgotos captados são direcionados para um sistema de tratamento e/ou disposição final adequados, evitando assim que o esgoto in natura seja encaminhado ao corpo hídrico principal, no caso as lagoas de Maricá (CONEN, 2016). 
Panorama do Sistema Lagunar de Maricá - RJ: Indicadores de Saneamento vs. Qualidade de Água

Em épocas de maiores chuvas, em função da maior diluição, o excesso de escoamento pode ser direcionado para a jusante da barragem, sem tratamento. Dependendo no nível de proteção desejado, podem ser feitas captações em série, na forma de um sistema/galeria de cintura, para proteger a Lagoa (Figura 10). Essa solução emergencial apresentou resultados positivos em outros sistemas lagunares próximos a região estudada, como nos casos das lagoas de Saquarema e Araruama, indicando que essa tecnologia possui bom potencial para ser implantada também em Maricá.

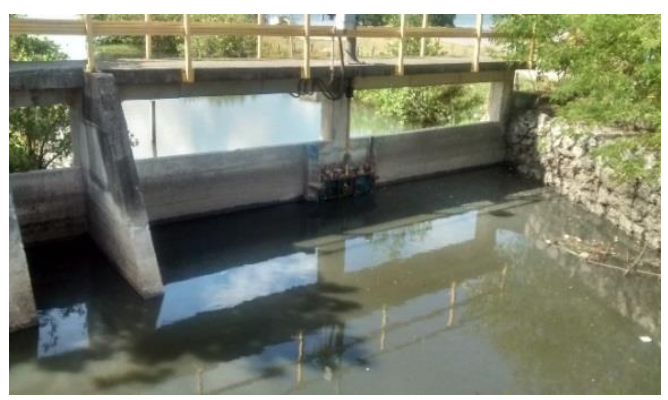

Figura 9 - Sistema de captação de tempo seco no Canal do Siqueira em Cabo Frio. Fonte: própria.

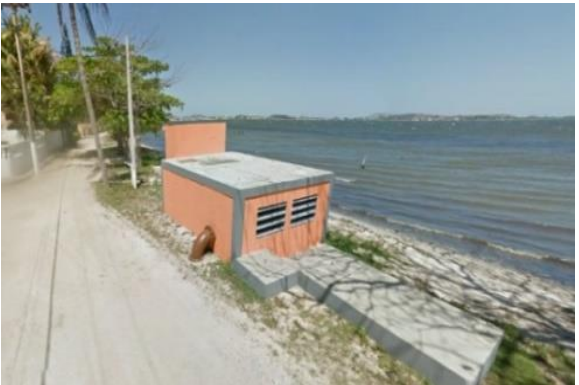

Figura 10 - Sistema de Galeria de cintura no entorno da Lagoa de Saquarema.

Fonte: própria.

Para que tal medida seja implantada de forma eficiente, deverão ser priorizados os corpos hídricos cujas condições apresentadas se mostram mais críticas em relação à qualidade de suas águas. Seguindo tal raciocínio, no caso de Maricá, as estruturas e tubulações das captações de tempo seco devem ser implantadas prioritariamente nos canais do Aeroporto e do Buriche.

Os esgotos deverão ser encaminhados a uma ETE com tratamento terciário para remoção de nutrientes, caso o destino final seja a Lagoa, ou tratamento primário caso seja utilizado o emissário submarino. À medida que a rede separativa for sendo construída, essas captações/sistemas emergenciais podem ser gradativamente desativadas.

Uma segunda alternativa seria a construção de sistemas de tratamento descentralizados em algumas regiões do município. Os sistemas de tratamento de esgotos descentralizados denominados Ecossistemas Engenheirados (SALOMÃo et al., 2012) aliam tecnologias individuais 
de tratamento descentralizado já popularizadas no Brasil, como o conjunto fossa séptica e filtro, com o tratamento por sistemas vegetados (wetlands), sendo possível aumentar a eficiência do tratamento descentralizado sem grandes impactos nos custos de implementação e manutenção. Estes sistemas podem ser aplicados no tratamento de esgotos de regiões de Maricá mais afastadas que com maiores dificuldades de acesso a um sistema de coleta e tratamento de efluentes centralizado/convencional.

São também recomendados investimentos em campanhas de conscientização e educação ambiental da população, tanto residente como flutuante, enfocando a importância do saneamento e o papel de cada morador quanto ao adequado funcionamento dos sistemas sanitários a serem implantados para a melhoria das condições ambientais e revitalização do SLM.

\section{CONCLUSÃO}

Maricá possui muitas deficiências em aspectos de planejamento e controle urbanístico, agravadas por um crescimento populacional e expansão urbana desordenada, que resultam em não conformidades no uso e ocupação de seu solo. Somada às enormes carências de saneamento constatadas, tal conjuntura influência direta e decisivamente na situação de degradação em que se encontram a grande maioria dos corpos hídricos locais e notadamente o SLM.

0 SLM vem sendo palco de frequentes florações de algas/eutrofização, além de mortandades de peixes, trazendo impactos sociais e econômicos negativos para a população do município. Tais ocorrências apresentam uma relação direta com a degradação das águas dos corpos hídricos locais e com a precariedade de atendimento do sistema de saneamento básico de Maricá.

0 canal do Aeroporto foi o local que apresentou sempre os piores IQA (todos "Péssimo", com exceção de "Ruim" em apenas uma ocasião). Essa classificação está relacionada justamente ao fato deste corpo hídrico atravessar as áreas mais urbanizadas do município de Maricá e receber grande vazão de esgotos sanitários sem qualquer tratamento.

De maneira análoga, os piores IQA avaliados em Saquarema foram apresentados pelo Rio do Padre, que assim como o canal do Aeroporto em Maricá, se encontra nas áreas mais urbanizadas do município.

Em relação aos indicadores de saneamento e IQA de suas respectivas lagoas, a comparação dos resultados dos municípios de Maricá e Saquarema, comprovam a existência de uma relação direta entre a falta de um sistema de saneamento adequado de Maricá e a 
Panorama do Sistema Lagunar de Maricá - RJ: Indicadores de Saneamento vs. Qualidade de Água

consequente degradação da qualidade das águas dos seus principais corpos hídricos receptores, que desaguam no SLM.

Portanto, maiores investimentos no saneamento do município são essenciais de forma a proporcionar sua maior abrangência, especialmente do sistema de esgotamento sanitário. Este ainda deverá considerar a necessidade de redução de nutrientes, caso o desague de efluente tratado se dê no SLM ou em corpos hídricos afluentes a ele.

\section{REFERÊNCIAS BIBLIOGRÁFICAS}

ABBASNIA, A. et al. Evaluation of groundwater quality using water quality index and its suitability for assessing water for drinking and irrigation purposes: Case study of Sistan and Baluchistan province (Iran). Human and Ecological Risk Assessment: An International Journal, v. 25, n. 4, p. 988-1005, 2019.

ABES - Associação Brasileira de Engenharia Sanitária e Ambiental. Ranking ABES da universalização do saneamento. Brasília, 2015, 2017, 2019.

ALEGRE, H.; HIRNER, W.; BAPTISTA, J.M.; PARENA, R. Performance indicators for water supply services. IWA publishing, 2016.

AMADOR, E. Breve parecer técnico sobre o Sistema Lagunar de Maricá. 2007, 2p.

AMBIENTAL. 2014 Relatório de Impacto Ambiental - RIMA Análise da viabilidade ambiental para implantação de um emissário terrestre e submarino para o transporte de efluentes domésticos, a ser localizado no município de Maricá/RJ.

http://www.inea.rj.gov.br/cs/groups/public/documents/document/zwew/mdi5/ edisp/inea0029326.pdf.

Acessado em_29/06/2019

ANA - AGÊNCIA NACIONAL DE ÁGUAS. Atlas Água e Esgotos. Brasília, 2017.

ANA - AGÊNCIA NACIONAL DE ÁGUAS. Indicadores de qualidade das águas. 2005. Disponível em http://portalpnqa.ana.gov.br/indicadores-indice-aguas.aspx. Acesso em: 30/06/2019.

ATLAS BRASIL. Atlas do desenvolvimento humano no Brasil. 2013 Disponível em http://atlasbrasil.org.br. Acessado em 15/06/2018.

BIDEGAIN, P. e PEREIRA L. F. M. Plano das bacias hidrográficas da região dos Lagos e do rio São João. Rio de Janeiro: CILSJ, 2005.

BRASIL, I.B.G.E. Instituto Brasileiro de geografia e Estatística. Censo demográfico. 2010.

BRASIL. CONSELHO NACIONAL DO MEIO AMBIENTE. Resolução n. ${ }^{\circ}$ 430, de 13 de maio de 2011. Dispõe sobre as condições e padrões de lançamento de efluentes, do Conselho Nacional do Meio Ambiente-CONAMA. Diário Oficial da União, n. 92, 2011.

BRASIL. Plano Nacional de Saneamento Básico. Brasília: Ministério das Cidades, 2013.

CETESB - COMPANHIA AMBIENTAL DO ESTADO DE SÃ0 PAUL0. Índice de Qualidade de Águas. 2003 Disponível em http://cetesb.sp.gov.br/?S=iqa. Acesso em: 15/07/2018.

CONEM. Empresa de projetos, gerenciamento e fiscalização de obras de infraestrutura urbana. 2016 Disponível em: http://conen.com.br. Acesso em: 10/08/2018

CONEM. Plano Municipal de Saneamento Básico de Maricá, de 2015. 
CRUZ, A. C. da. Análise de intervenções no sistema lagunar de Maricá-RJ com auxílio de modelagem hidrodinâmica ambiental. 2010. 74 p. COPPE, Universidade Federal do Rio de Janeiro, Rio de Janeiro, 2010.

CRUZ, C. B. M., et al. Impactos ambientais no sistema lagunar de Maricá-Guarapina. In: VII SIMPÓSIO BRASILEIRO DE SENSORIAMENTO REMOT0, 1996, Salvador. Anais... Salvador: INPE, 1996. p. 137-141.

FRANCO, T.P.; NEVES, L.M.; ARAÚJ0, F.G. Better with more or less salt? The association of fish assemblages in coastal lagoons with different salinity ranges. Hydrobiologia, v. 828, n. 1, p. 83-100, 2019.

GIORDANO, G.; OBRACZKA, M.; DE SOUZA, M.; MELLO, M.; MARQUES, C. Environmental Monitoring of Water Quality as a Planning and Management Tool: A Case Study of the Rodrigo de Freitas Lagoon, Rio de Janeiro, Brazil. In: Lagoon Environments Around the World-A Scientific Perspective. Intech Open, 2019.

INEA - INSTITUTO ESTADUAL D0 AMBIENTE. Disponível em http://www.inea.rj.gov.br/. Acessado em 15/04/2018. LOUREIR0, D.S.; MATIAS, M.L.; FREIRE, D.G. Avaliação do conflito sócio-ambiental na APA da restinga de Maricá. Porto Alegre/RS. 2010.

MUKATE, Shrikant et al. Development of new integrated water quality index (IWQI) model to evaluate the drinking suitability of water. Ecological indicators, v. 101, p. 348-354, 2019.

OHNUMA JR, A. A. et al. Análise de potencial do aproveitamento de água de chuva para uso doméstico em sistemas individuais localizados no município de Maricá-RJ. In: XXIII SBRH - Simpósio Brasileiro de Recursos Hídricos, 2019, Foz do Iguaçú. Água Conecta. Porto Alegre: ABRH, 2019. v. 1. p. 1-10.

ROSS0, T.C.A. Aspectos institucionais da gestão da bacia hidrográfica da Lagoa Rodrigo de Freitas. 2008. Disponível em: http:// www.meioambiente.uerj.br/destaque/ artigo_lagoa.htm. Acesso em: 15/04/2020.

SALOMÃO, A.L.S.; MARQUES, M.; SEVERO, R.G.; ROQUE, O.C.C. Engineered ecosystem for on-site wastewater treatment in tropical areas. Water Sci. Technol. 66, 2131-2137, 2012

SNIS - SISTEMA NACIONAL DE INFORMAÇÕES SOBRE O SANEAMENTO. Dados sobre saneamento nacional. Disponível em http://www.snis.gov.br/. Acesso em 21/06/2018.

STAHRE, P.; ADAMSSON, J. Performance benchmarking. A powerful management tool for water and wastewater utilities. WATERMARQUE, 2004

TIAN, Y. et al. Using a water quality index to assess the water quality of the upper and middle streams of the Luanhe River, northern China. Science of the Total Environment, v. 667, p. 142-151, 2019.

VON SPERLING, M. Introdução à qualidade das águas e ao tratamento de esgotos. 3. ed. Minas Gerais: UFMG, 2005.

VON SPERLING, T.L.; VON SPERLING, M. Proposição de um sistema de indicadores de desempenho para avaliação da qualidade dos serviços de esgotamento sanitário. Engenharia Sanitária e Ambiental, Rio de Janeiro, v. 18, n. 4, p. 313-322, 2013.

WALL, F.C.M., TOLEDO, L.M., OBRACZKA, M. Panorama ambiental do Sistema Lagunar de Maricá - RJ a partir da avaliação de indicadores de saneamento e índices de qualidade de água. In: II SEMINÁRIO NACIONAL DE RECURSOS HÍDRICOS E SANEAMENT0 AMBIENTAL, 2019, Espírito Santo. Anais Associação Brasileira de Engenharia Sanitária e Ambiental seção Espírito Santo, 2019. 